\title{
Microstructure and Mechanical Properties of a TRIP-Aided Martensitic Steel
}

\author{
Koh-ichi Sugimoto ${ }^{1} \cdot$ Ashok Kumar Srivastava $^{2}$
}

Received: 28 May 2015/Revised: 22 July 2015/Accepted: 21 August 2015/Published online: 3 September 2015

(C) The Author(s) 2015. This article is published with open access at Springerlink.com

\begin{abstract}
This paper deals with the microstructural and mechanical properties of a transformation-induced plasticity-aided martensitic (TM) steel that is expected to serve as an advanced structural steel for automotive applications. The microstructure consisted of a wide lath-martensitestructured matrix and a mixture of narrow lath-martensite and metastable retained austenite of 2-5 vol\% (MA-like phase). When $1 \% \mathrm{Cr}$ and $1 \% \mathrm{Cr}-0.2 \%$ Mo were added into $0.2 \% \mathrm{C}-1.5 \% \mathrm{Si}-1.5 \% \mathrm{Mn}$ steel to enhance its hardenability, the resultant TM steels achieved a superior cold formability, toughness, fatigue strength, and delayed fracture strength as compared to conventional structural steel such as SCM420. These enhanced mechanical properties were found to be mainly caused by (1) plastic relaxation of the stress concentration, which resulted from expansion strain on the strain-induced transformation of the metastable retained austenite, and (2) the presence of a large quantity of a finely dispersed MA-like phase, which suppressed crack initiation or void formation and subsequent void coalescence.
\end{abstract}

Keywords Automotive applications - Microstructure . Mechanical property - TRIP-aided martensitic steel . Retained austenite $\cdot$ Microalloying

Koh-ichi Sugimoto sugimot@shinshu-u.ac.jp

1 Department of Mechanical Systems Engineering, Shinshu University, 4-17-1 Wakasato, Nagano 380-8553, Japan

2 Department of Metallurgical Engineering, O. P. Jindal University, Punjipathra, Raigarh, Chhattisgarh 496001, India

\section{Introduction}

In the past decade, some advanced high-strength and ultrahigh-strength sheet steels (AHSS and AUHSS, respectively) such as transformation-induced plasticity (TRIP) [1] -aided sheet steel [2-11], quench and partitioning steel [12, 13], and twinning-induced plasticity (TWIP) steel [14] have been developed in order to reduce the weight and improve the impact safety of automobiles. General ultrahigh-strength TRIP-aided steels such as TRIP-aided bainitic ferrite (TBF) steel are produced by an isothermal transformation (IT) process at a temperature above the martensite-start temperature $\left(M_{\mathrm{s}}\right)$ or at a temperature between $M_{\mathrm{s}}$ and the martensitefinish temperature $\left(M_{\mathrm{f}}\right)$ [6]. Sugimoto et al. [8] reported that the microstructure of TBF steel changed to a wide lathmartensite matrix and a large amount of finely dispersed narrow lath-martensite and metastable austenite (MA-like phase) when the IT process was carried out at temperatures lower than $M_{\mathrm{f}}$. Such a TRIP-aided martensitic (TM) steel attained a superior combination of tensile strength and formability [8]. Combinations of tensile strength and total elongation of some of the abovementioned AHSS and AUHSS steels are controlled by the original volume fraction of austenite and retained austenite, as shown in Fig. 1.

Because TM steel also possesses superior mechanical properties such as toughness [15-17], fatigue strength [18, 19], and hydrogen embrittlement resistance [20] as compared to conventional structural steel (Fig. 2), application of TM steel to automotive drivetrain components such as gears, drive shafts, $\mathrm{CV}$ joints, clutch plates, etc. is expected to reduce the weight and $\mathrm{CO}_{2}$ emission.

This paper introduces the microstructural and mechanical properties of $\mathrm{C}-\mathrm{Si}-\mathrm{Mn}$ TM steels with different $\mathrm{C}, \mathrm{Mn}$, $\mathrm{Cr}, \mathrm{Mo}, \mathrm{Ni}, \mathrm{Nb}$, and $\mathrm{B}$ contents, which affect the hardenability of the steel, in order to assess the suitability of such 


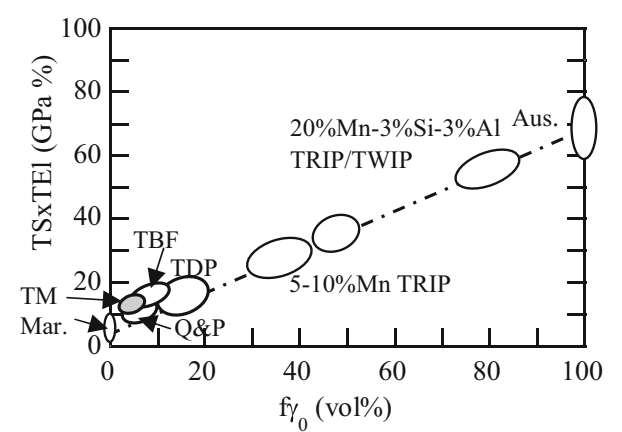

Fig. 1 Relationship between a combination of the tensile strength and total elongation (TS $\times \mathrm{TEl}$ ) and the original volume fraction of austenite and retained austenite $\left(f \gamma_{0}\right)$, in various TRIP and TWIP steels. TDP TRIP-aided dual-phase steel, TBF TRIP-aided bainitic ferrite steel, $T M$ TRIP-aided martensitic steel, $Q \& P$ Quenching and partitioning steel, Mar conventional martensitic steel, Aus austenitic steel

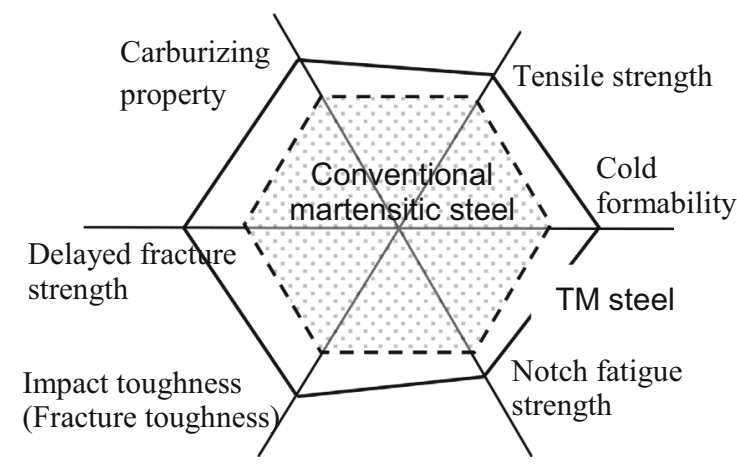

Fig. 2 Comparison of the mechanical properties of TM steel and conventional martensitic steel

steels for application to automotive structural parts and drivetrain components.

\section{Materials and Experimental Procedure}

The chemical compositions of the steels used in this study are listed in Table 1. Steel A is a base steel with a chemical composition of $0.2 \% \mathrm{C}, 1.5 \% \mathrm{Si}, 1.5 \% \mathrm{Mn}$, and $0.05 \% \mathrm{Nb}$ (mass\%). The addition of $\mathrm{Mn}, \mathrm{Cr}, \mathrm{Mo}, \mathrm{Ni}, \mathrm{Nb}$, and/or B to this created Steels B-H. In Steels I-M, Nb was omitted and the carbon content was varied.

Figure 3 illustrates the heat-treatment diagram of TM steel, which consisted of austenitizing followed by an isothermal transformation (IT) process at temperatures below the martensite-finish temperature $\left(M_{\mathrm{f}}\right)$. In some instances, a final partitioning process was also conducted at $250-350{ }^{\circ} \mathrm{C}$ for $1000 \mathrm{~s}$ in order to promote carbon enrichment of the retained austenite.

The microstructures of the steels were observed by transmission electron microscopy (TEM) and field-emission scanning electron microscopy (FE-SEM), which was performed using an instrument equipped with an electron backscatter diffraction (EBSD) system. The steel specimens for the FE-SEM-EBSD analyses were first ground with alumina powder and colloidal silica, and then ion thinning was performed.

The retained austenite characteristics of the steels were evaluated by x-ray diffractometry. The volume fractions of the retained austenite phases $\left(f_{\gamma}\right.$, vol\%) were quantified from the integrated intensity of the (200) $\alpha,(211) \alpha,(200) \gamma$, (220) $\gamma$, and (311) $\gamma$ peaks obtained by x-ray diffractometry using Mo-K $\alpha$ radiation [21]. The carbon concentrations $\left(C_{\gamma}\right.$, mass $\%$ ) of the retained austenite phases were estimated from the empirical equation proposed by Dyson and Holmes [22]. In this case, the lattice constant $\left(a_{\gamma}, \times 0.1 \mathrm{~nm}\right)$ was measured from the (200) $\gamma,(220) \gamma$, and (311) $\gamma$ peaks of $\mathrm{Cu}$ $\mathrm{K} \alpha$ radiation.

The tensile tests were performed at $298 \mathrm{~K}\left(25^{\circ} \mathrm{C}\right)$ using a tensile testing machine under a crosshead speed of $1 \mathrm{~mm} /$ min (resulting in a strain rate of $6.67 \times 10^{-4} \mathrm{~s}^{-1}$ ).

Hole punch and hole expansion tests were carried out using a graphite-type lubricant [8]. A hole with a diameter of $4.76 \mathrm{~mm}$ was punched out at a punching rate of $10 \mathrm{~mm} /$ min $\left(\right.$ at $25^{\circ} \mathrm{C}$ ), with a clearance of $10 \%$ between the die and the punch. Successive hole expansion tests were performed at $25^{\circ} \mathrm{C}$ using a $60^{\circ}$ conical die at a punching rate of $1 \mathrm{~mm} / \mathrm{min}$. In the expansion tests, the punch was contacted with the rollover section of the hole punch specimens. The hole expansion ratio $(\lambda)$ was determined by the following equation,

$\lambda=\left\{\left(d_{\mathrm{f}}-d_{0}\right) / d_{0}\right\} \times 100 \%$,

where $d_{0}$ and $d_{\mathrm{f}}$ are the initial hole diameter and hole diameter after cracking, respectively. Stretch forming tests were performed on the same specimens that were subjected to the stretch flanging tests to measure the maximum stretch height, $H_{\max }$, without cracking. The punching rate was $1 \mathrm{~mm} / \mathrm{min}$; a cylindrical punch with a diameter of $17.6 \mathrm{~mm}$ and a curvature radius of $8.7 \mathrm{~mm}$ was used. Bending tests were carried out by means of the V-block method. The $\mathrm{V}$-punch angle was $90^{\circ}$, and the radius was varied from 0.5 to $5.0 \mathrm{~mm}$. The bendability was defined by the minimum bending radius, $R_{\min }$, up to which the specimen could bend without cracking. In the above mentioned forming tests, two or three sheets were prepared for each test. All the tests were conducted at $25{ }^{\circ} \mathrm{C}$.

The impact tests were conducted on a Charpy impact testing machine for temperatures in the range of 77-373 K $\left(-196\right.$ to $\left.100{ }^{\circ} \mathrm{C}\right)$. Liquid nitrogen, dry ice, ethyl alcohol, and water were used to cool and warm the specimens. The impact properties were evaluated by determining the Charpy impact absorbed value (CIAV) and ductile-brittle transition temperature (DBTT) of the specimens [15-17]. 
Table 1 Chemical compositions of steels used (mass\%)

\begin{tabular}{|c|c|c|c|c|c|c|c|c|c|c|c|c|c|}
\hline Steel & $\mathrm{C}$ & $\mathrm{Si}$ & Mn & $\mathrm{P}$ & S & $\mathrm{Al}$ & $\mathrm{Nb}$ & $\mathrm{Cr}$ & Mo & $\mathrm{Ni}$ & B & $\mathrm{N}$ & $\mathrm{O}$ \\
\hline A & 0.20 & 1.50 & 1.51 & 0.004 & 0.0020 & 0.044 & 0.050 & $\ldots$ & $\ldots$ & $\ldots$ & $\ldots$ & 0.0013 & 0.0007 \\
\hline B & 0.20 & 1.52 & 1.50 & 0.004 & 0.0021 & 0.039 & 0.005 & $\ldots$ & $\ldots$ & $\ldots$ & 0.0018 & 0.0011 & 0.0010 \\
\hline $\mathrm{C}$ & 0.21 & 1.49 & 1.50 & 0.004 & 0.0019 & 0.040 & 0.050 & 0.50 & $\ldots$ & $\ldots$ & $\ldots$ & 0.0012 & 0.0012 \\
\hline $\mathrm{D}$ & 0.20 & 1.49 & 1.50 & 0.004 & 0.0019 & 0.040 & 0.050 & 1.00 & $\ldots$ & $\ldots$ & $\ldots$ & 0.0012 & 0.0012 \\
\hline $\mathrm{E}$ & 0.18 & 1.48 & 1.49 & 0.004 & 0.0029 & 0.043 & 0.050 & 1.02 & 0.20 & $\ldots$ & $\ldots$ & 0.0010 & 0.0015 \\
\hline $\mathrm{F}$ & 0.21 & 1.49 & 1.49 & 0.003 & 0.0019 & 0.034 & 0.049 & 1.00 & 0.20 & 1.52 & $\ldots$ & 0.0014 & 0.0009 \\
\hline $\mathrm{G}$ & 0.20 & 1.52 & 2.98 & 0.006 & 0.0016 & 0.037 & $\ldots$ & $\ldots$ & $\ldots$ & $\ldots$ & $\ldots$ & 0.0034 & $<0.001$ \\
\hline $\mathrm{H}$ & 0.21 & 1.50 & 4.94 & 0.005 & 0.0016 & 0.032 & $\ldots$ & $\ldots$ & $\ldots$ & $\ldots$ & $\ldots$ & 0.0020 & $<0.001$ \\
\hline I & 0.10 & 1.49 & 1.50 & 0.015 & 0.0015 & 0.039 & $\ldots$ & $\ldots$ & $\ldots$ & $\ldots$ & $\ldots$ & 0.0007 & 0.0007 \\
\hline $\mathrm{J}$ & 0.20 & 1.51 & 1.51 & 0.015 & 0.0011 & 0.040 & $\ldots$ & $\ldots$ & $\ldots$ & $\ldots$ & $\ldots$ & 0.0012 & 0.0012 \\
\hline K & 0.29 & 1.50 & 1.50 & 0.014 & 0.0012 & 0.040 & $\ldots$ & $\ldots$ & $\ldots$ & $\ldots$ & $\ldots$ & 0.0013 & 0.0014 \\
\hline $\mathrm{L}$ & 0.40 & 1.49 & 1.50 & 0.015 & 0.0012 & 0.043 & $\ldots$ & $\ldots$ & $\ldots$ & $\ldots$ & $\ldots$ & 0.0010 & 0.0015 \\
\hline M & 0.61 & 1.50 & 1.53 & 0.015 & 0.0011 & 0.034 & $\ldots$ & $\ldots$ & $\ldots$ & $\ldots$ & $\ldots$ & 0.0014 & 0.0009 \\
\hline
\end{tabular}

[isothermal transformation process] [partitioning process]



Fig. 3 Profile showing the heat treatment (isothermal transformation and partitioning process) to which the alloyed steels were subjected. $O Q$ quenching in oil

Fatigue tests were carried out using a multi-type fatigue testing machine at $25^{\circ} \mathrm{C}$, with a sinusoidal wave of $80 \mathrm{~Hz}$. The stress ratio, defined as the ratio of minimum stress $\left(\sigma_{\min }\right)$ to maximum stress $\left(\sigma_{\max }\right)$ was $R=0.1[18,19]$. The fatigue limit was defined by the maximum value of the stress amplitude $\left(\sigma_{\mathrm{R}}=\sigma_{\max }-\sigma_{\min }\right)$ without failure up to $1.0 \times 10^{7}$ cycles.

Hydrogen embrittlement tests were carried out on the Instron type tensile testing machine at $25{ }^{\circ} \mathrm{C}$ and at crosshead speed of $1 \mathrm{~mm} / \mathrm{min}$ before and after hydrogen charging using tensile specimens. Hydrogen embrittlement property was evaluated by hydrogen embrittlement susceptibility (HES) estimated by the following equation.

$\mathrm{HES}=\left(1-\varepsilon_{\mathrm{c}} / \varepsilon_{0}\right) \times 100 \%$,

where $\varepsilon_{0}$ and $\varepsilon_{\mathrm{c}}$ represent total elongation before and after hydrogen charging, respectively. Hydrogen charging to the tensile specimens was conducted by the cathode charging method [20]. Diffusible hydrogen was measured by thermal desorption spectrometry analysis.

\section{Microstructure and Retained Austenite Characteristics}

Figure 4 shows typical image quality distribution maps obtained by the FE-SEM-EBSD analyses for Steel D after it was subjected to an IT process at $450{ }^{\circ} \mathrm{C}$ (for TBF steel) or $50{ }^{\circ} \mathrm{C}$ (for $\mathrm{TM}$ steel) [9]. This figure reveals that the microstructure of the TM steel consisted of a wide lathmartensite matrix and a fine MA-like phase dispersed primarily along prior austenitic, packet, and block boundaries (Fig. 4b) when the steel was subjected to an IT process at a temperature below $M_{\mathrm{f}}$. MA-like phase corresponding to lower image quality index than 4250 consisted of narrow lath-martensite structure and fine retained austenite. It was supposed that most of the retained austenite was located along the narrow martensite lath boundary. A small amount of carbide precipitated only in the wider lath-martensite structure (Fig. 4c).

The IT process temperature dependencies of the initial volume fraction and carbon concentration of the retained austenite, and volume fractions of MA-like phase and carbide in the TM steel (Steel A) are shown in Fig. 5(a, b). The volume fraction of retained austenite at a constant carbon concentration increased with increasing temperature in the IT temperature range of $25-250{ }^{\circ} \mathrm{C}$. Most of the retained austenite phase was estimated to be located along the narrow lath-martensite boundary by means of TEM observation. It is noteworthy that the MA-like phase fraction increased with increasing temperature of the IT process, although the carbide fraction decreased with increasing temperature of the IT process (Fig. 5b), because they influence the dispersion, size and hardness and thereby affect the strain-hardening behavior and void-initiation and -growth behavior. The carbide fraction was much lower 

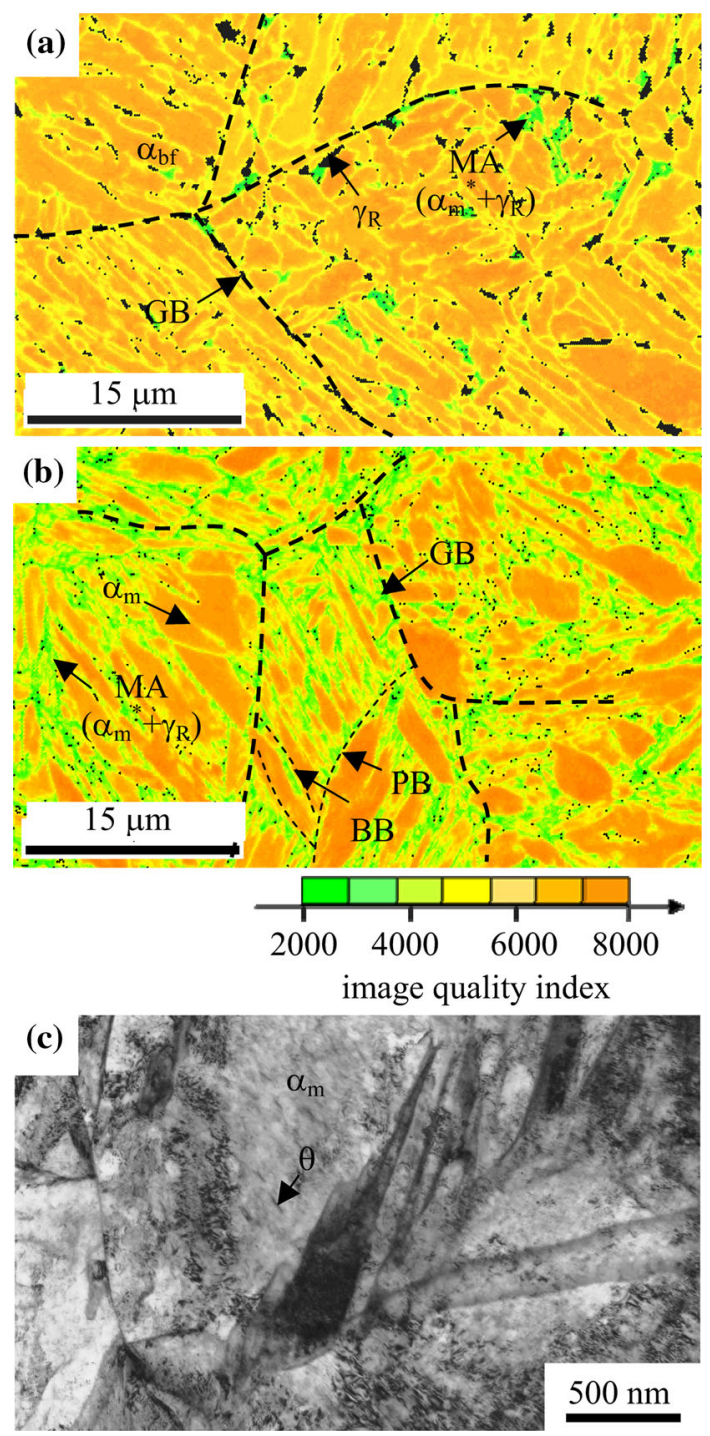

Fig. 4 Image quality (IQ) distribution maps of the matrix ( $\alpha$-Fe(bcc)) of (a) TBF (Steel D, $T_{\mathrm{IT}}=450{ }^{\circ} \mathrm{C}$ ) and (b) TM steels (Steel D, $T_{\mathrm{IT}}=50^{\circ} \mathrm{C}$ ) and (c) TEM image of TM steel (Steel D, $T_{\mathrm{IT}}=200^{\circ}-$ C). MA-like phase consists of narrow lath-martensite $\left(\alpha_{\mathrm{m}}^{*}\right)$ structure and $\gamma_{\mathrm{R}}$. GB, $\mathrm{PB}$, and $\mathrm{BB}$ represent the prior austenitic grain, packet, and block boundaries, respectively

than that of $0.2 \% \mathrm{C}-0.2 \% \mathrm{Si}-0.9 \% \mathrm{Mn}-1.0 \% \mathrm{Cr}-0.2 \% \mathrm{Mo}$ (SCM420) steel, as reported by Sugimoto et al. [7]. According to De Cooman et al. [23], the carbides are transition carbides or cementites. In some TRIP-aided steels, the stability of the retained austenite can be evaluated by the strain-induced transformation factor, $k$, which is defined by the following equation rather than the carbon concentration $[3,6]$ :

$\log f_{\gamma}=\log f_{\gamma 0}-k \varepsilon$,

where $f_{\gamma}$ is the volume fraction of retained austenite after being subjected to plastic strain, $\varepsilon$, and $f_{\gamma 0}$ is the original volume fraction of the retained austenite. The $k$ value



Fig. 5 Variations in (a) initial volume fraction $\left(f_{\gamma 0}\right)$ and initial carbon concentration $\left(C_{\gamma 0}\right)$ of retained austenite, (b) volume fractions of carbide $\left(f_{\theta}\right)$ and MA-like phase $\left(f_{\mathrm{MA}}\right)$, and (c) strain-induced transformation factor $(k)$ as a function of temperature of isothermal transformation process $\left(T_{\mathrm{IT}}\right)$ in TM steel (Steel A)

showed a tendency opposite that of the carbon concentration of the retained austenite (Fig. 5c).

The above mentioned microstructural change of TM steel with IT temperature below $M_{\mathrm{f}}$ and cooling temperature is illustrated in Fig. 6 and summarized as follows [911]:

Stages 1-3 When the steel was cooled to $T_{3}$, a temperature lower than the $M_{\mathrm{S}}$ temperature, after austenitization, the volume fraction of the wide lath-martensite structure $\left(f \alpha_{\mathrm{m}}\right)$ formed is defined by Eq 4 [24] (see Fig. 6c).

$f \alpha_{\mathrm{m}}=1-\exp \left\{-\mathrm{A}\left(M_{\mathrm{S}}-T_{3}\right)^{\mathrm{B}}\right\}$,

where $\mathrm{A}$ and $\mathrm{B}$ are material constants. $M_{\mathrm{S}}$ is the martensitestart temperature. During cooling, a part of the supersaturated solute carbon in the wide lath-martensite structure diffuses into the untransformed austenite phase, and a slightly carbon-enriched austenite phase is formed (stages 2-3 in Fig. 6d).

Stages 3-4 A small amount of carbide precipitates in the wide lath-martensite structure because of auto-tempering (stages 3-4 in Fig. 6d). Simultaneously, most of the untransformed austenite is transformed to a narrow lathmartensite structure (or MA-like phase). The carbon concentration of the narrow lath-martensite structure is higher than that of the wide lath-martensite structure. No carbide precipitates in the narrow lath-martensite structure. 

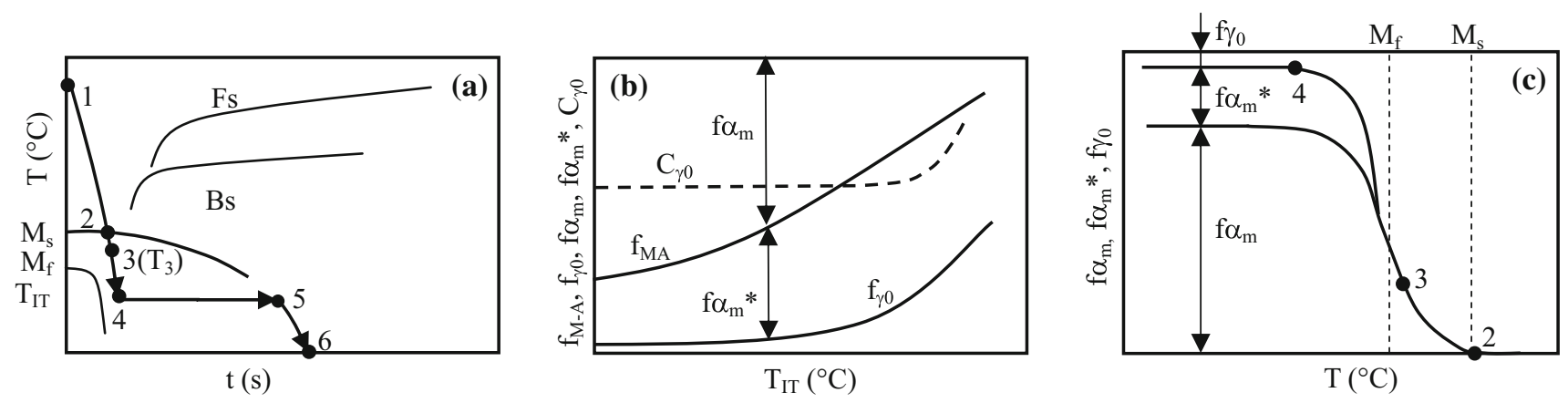

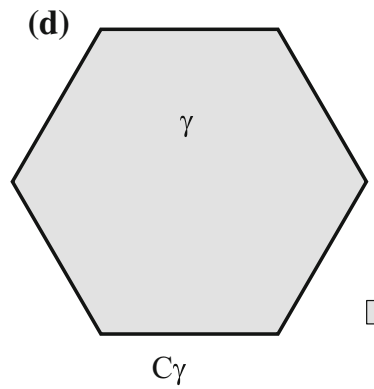

[stage 1]

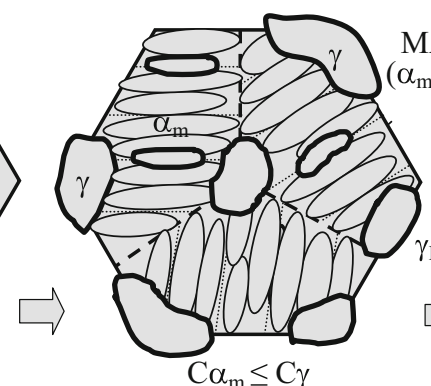

[stages 2-3]

transformation of $\gamma$ into $\alpha_{m}$

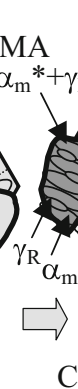

$$
\mathrm{C} \alpha_{\mathrm{n}}
$$

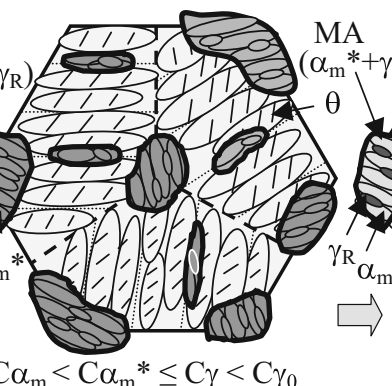

[stages 3-4] auto-tempering of $\alpha_{\mathrm{m}}$ (carbide precipitation) carbon-enrichment into $\gamma$ from $\alpha_{\mathrm{m}}$ transformation of $\gamma$ into $\alpha_{m} *$

Fig. 6 (a) Heat-treatment diagram, (b) IT temperature $\left(T_{\mathrm{IT}}\right)$ dependencies of initial volume fraction $\left(f_{\gamma 0}\right)$ and carbon concentration $\left(C_{\gamma 0}\right)$ of retained austenite, volume fraction of austenite $\left(f_{\gamma}\right)$, wide lathmartensite $\left(f \alpha_{\mathrm{m}}\right)$, narrow lath-martensite $\left(f \alpha_{\mathrm{m}}^{*}\right)$, and MA-like phase $\left(f_{\mathrm{MA}}\right),(\mathbf{c})$ variations in $f \alpha_{\mathrm{m}}, f \alpha_{\mathrm{m}}^{*}$, and $f_{\gamma 0}$ with cooling temperature $(T)$, and (d) microstructural change in stages 1-6 during heat treatment in

Stages 4-6 Supersaturated solute carbon in the narrow lath-martensite structure diffuses into the retained austenite in the MA-like phase and promotes carbon enrichment of the retained austenite, similar to the case of the wide lathmartensite structure (stages 4-6 in Fig. 6d).

Considering the above mentioned microstructural change, the high volume fractions of the retained austenite and MA-like phase of TM steel subjected to IT at $200{ }^{\circ} \mathrm{C}$ (Fig. 6b) may be associated with an increase in the untransformed austenite fraction. The high carbon concentration of the retained austenite (about 0.6 mass $\%$ ) may be due to the low carbide fraction, which increases the effective solute carbon diffusing from the wide lathmartensite structure into the retained austenite.

\section{Tensile Properties}

The typical stress-strain curves of the TRIP-aided steel are shown in Fig. 7 [10]. The tensile properties are shown in Fig. 8. When IT was conducted in the range of $25-200{ }^{\circ} \mathrm{C}$, steel D, where $\alpha_{\mathrm{m}}, \alpha_{\mathrm{m}}^{*}, \gamma, \gamma_{\mathrm{R}}, \theta$, MA, and C represent wide lathmartensite, narrow lath-martensite, austenite, retained austenite, carbide, MA-like phase, and solute carbon, respectively. $\mathrm{C} \gamma, \mathrm{C} \alpha_{\mathrm{m}}$, and $\mathrm{C} \alpha_{\mathrm{m}}^{*}$ are the carbon concentrations in austenite, wide lathmartensite, and narrow lath-martensite, respectively

the tensile strength exceeded 1.5 GPa, although the tensile strength (TS) and yield stress (0.2\% offset proof stress) decreased with increasing IT temperature (Fig. 8a). It is noteworthy that the higher the IT temperature, the lower the flow stress in the early stage (Fig. 7a). In addition, the total elongation and reduction of area tended to increase with increasing IT temperature.

Similar to TRIP-aided steels with different matrix structures, the increment of strain-hardening $\left(\Delta \sigma_{\mathrm{h}}\right)$ of TM steel may consist of the following, $\sigma_{\mathrm{i}}, \sigma_{\mathrm{t}}$, and $\sigma_{\mathrm{f}}[4,25]$, which are the "mean internal stress" (or long-range internal stress), "strain-induced martensite hardening" [4], and "forest-hardening," respectively, proposed by Ashby [26]:

$\sigma_{\mathrm{i}}(\varepsilon)=\{(7-5 v) \mu / 5(1-v)\} \cdot f \cdot \varepsilon_{\mathrm{P}}^{\mathrm{u}}$

$\sigma_{\mathrm{t}}(\varepsilon)=g\left(f \alpha_{m}^{*}\right)$

$\sigma_{\mathrm{f}}(\varepsilon)=\zeta \mu(b \cdot f \cdot \varepsilon / 2 r)^{1 / 2}$,

where $v$ and $\mu$ are the Poisson's ratio and the shear modulus of each phase, respectively, $\varepsilon_{\mathrm{P}}^{\mathrm{u}}$ is the "eigen strain" [27], $f$ is the volume fraction of the second phase, and $g\left(f \alpha_{\mathrm{m}}^{*}\right)$ is 

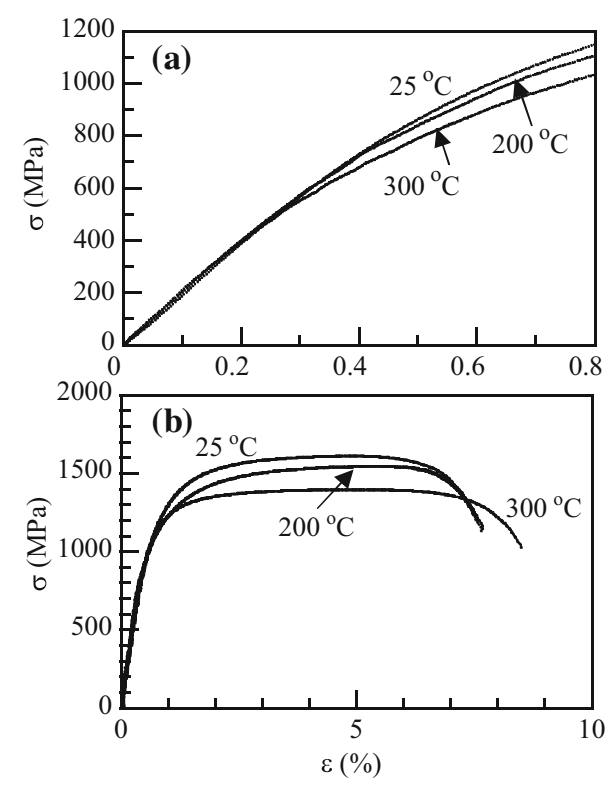

Fig. 7 Nominal stress-strain $(\sigma-\varepsilon)$ curves of TM steel (Steel A) subjected to the IT process at $T_{\mathrm{IT}}=50,200$, and $300{ }^{\circ} \mathrm{C}$. (a) initial stage, (b) full curves
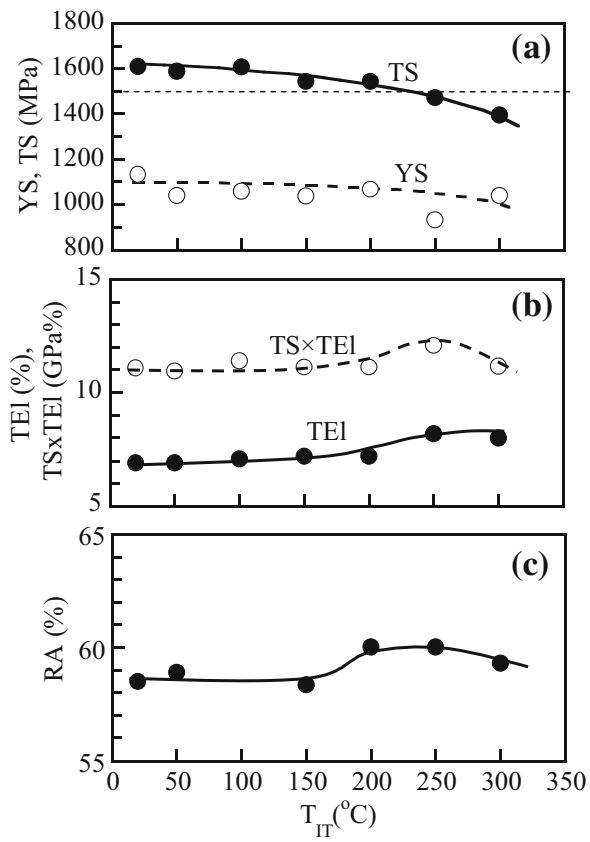

Fig. 8 Variations in (a) yield stress or $0.2 \%$ offset proof stress (YS) and tensile strength (TS), (b) total elongation (TEl) and combination of strength and elongation (TS $\times \mathrm{TEl}$ ), and (c) reduction of area (RA) as a function of temperature of isothermal transformation process $\left(T_{\mathrm{IT}}\right)$ in TM steel (Steel A)

obtained as a function of the volume fraction of the straininduced martensite content, $f \alpha_{\mathrm{m}}^{*}$. The term $\zeta$ is a constant, $\boldsymbol{b}$ is the Burgers vector, and $r$ denotes the mean diameter of the second-phase particles. Because the microstructure of
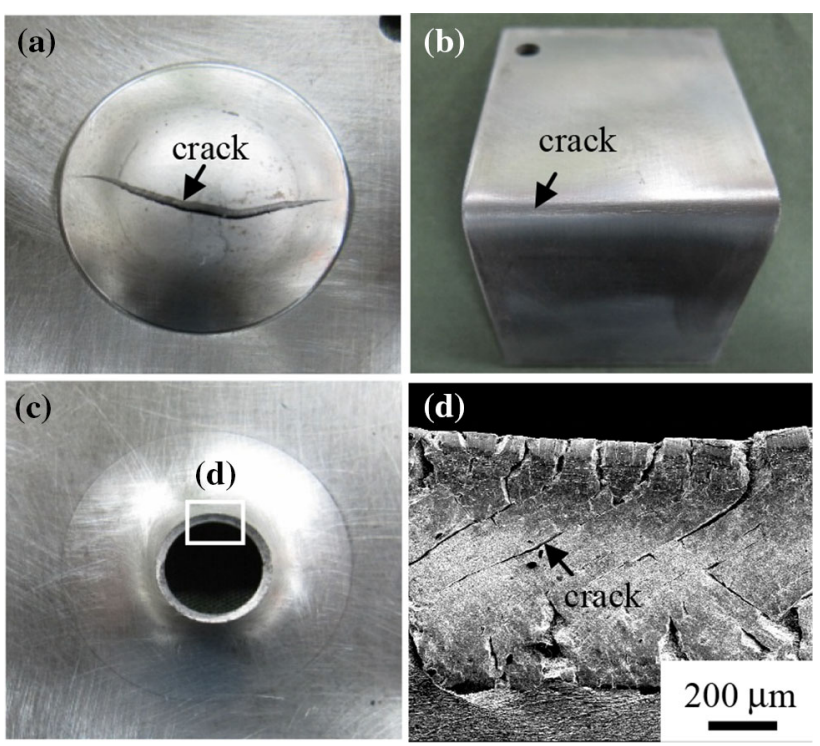

Fig. 9 Typical photographs of cold-formed specimens. (a) Stretch forming, (b) bending tests ( $2 \mathrm{~mm}$ radius), and (c, d) stretch flanging performed on TM steel (steel A) subjected to an IT process at $200^{\circ} \mathrm{C}$. (d) High-magnification image of the region marked by the square in (c)

TM steel is composed of a soft matrix (wide lath-martensite) and a hard second phase (MA-like phase), high compressive internal stress, which results from a difference in flow stresses between the matrix and the second phase, takes place in the matrix [28].

\section{Cold Formability}

Figure 9 shows a typical fracture in TM steel (Steel A) after stretch forming, stretch flanging, and bending tests. Some of the cracks are straight in the specimens after stretch forming and stretch flanging tests, and any necking is not observed because of relatively small local elongation, as shown in Fig. 9(c) [10]. Figure 10 shows the variations in the $H_{\max }, \lambda$, and $R_{\min }$ as a function of the temperature of the IT process in TM steel (Steel A) [10]. The $H_{\max }$ and $\lambda$ monotonically increased with increasing IT temperature. On the other hand, the $R_{\min }$ decreased only when the IT temperature was $300{ }^{\circ} \mathrm{C}$, but it remained constant at temperatures between 25 and $250{ }^{\circ} \mathrm{C}$. When the IT process was conducted at $200{ }^{\circ} \mathrm{C}$, punching damage such as void or crack formation was suppressed and the shear section length was larger than that during the IT process at $25{ }^{\circ} \mathrm{C}$. Such a low punching damage is considered to bring on the good stretch flangeability.

Sugimoto et al. [8] reported that the stretch flangeability of TM steel is associated with (1) a softened wide lathmartensite structure with a low carbide fraction and (2) plastic relaxation of the localized stress concentration by 

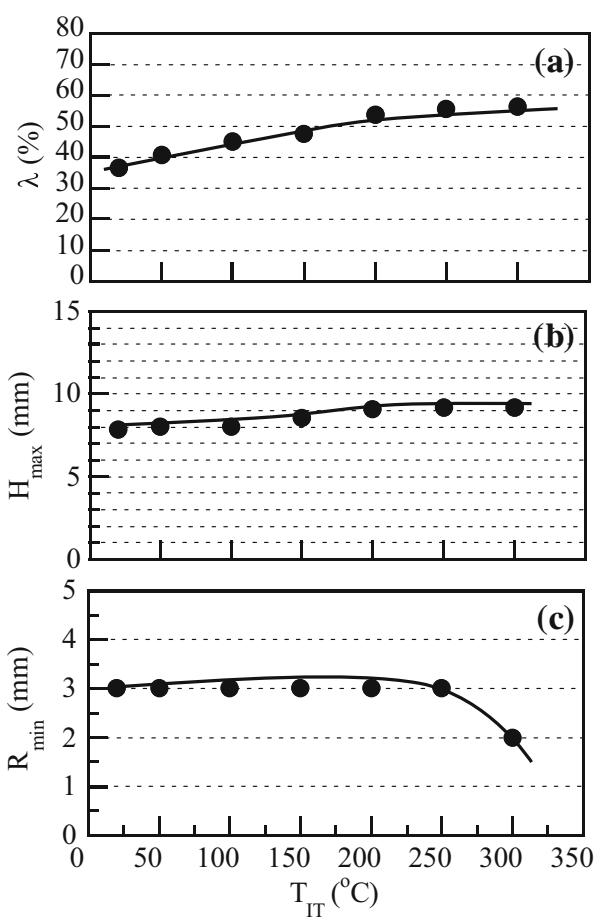

Fig. 10 Variations in (a) hole expansion ratio $(\lambda)$, (b) maximum stretch height $\left(H_{\max }\right)$, and $(\mathbf{c})$ minimum bending radius $\left(R_{\min }\right)$ as a function of temperature of IT process $\left(T_{\mathrm{IT}}\right)$ in TM steel (Steel A)

the strain-induced transformation of finely dispersed metastable retained austenite in the MA-like phase. These two characteristics influence both the hole-surface layer damage on punching and the localized ductility on expanding.

The TM steel subjected to IT at $200{ }^{\circ} \mathrm{C}$ was characterized by a small degree of damage to the punched hole surface or by a low density of voids and a long shear section. This may lead to higher stretch flangeability in the TRIP-aided steel and 4 vol\% metastable retained austenite, which contributes to a large fracture strain upon stretch expansion. In this case, the small punching damage may be associated with a softened wide lath-martensite matrix and the small amount of carbide, which suppressed void formation in the wide lath-martensite.

Figure 11 compares the two kinds of formability of the TM steels used in this study with those of a conventional ferrite-martensite dual-phase and 22MnB5 martensitic steels. At tensile strengths exceeding $1.5 \mathrm{GPa}$, the TRIPaided steel, to which $1 \% \mathrm{Cr}$ and $1 \% \mathrm{Cr}-0.2 \% \mathrm{Mo}$ were added to the base steel, attained the best formability, especially when subjected to an IT process at $200{ }^{\circ} \mathrm{C}$, which corresponds to the optimum IT process temperature $\left(M_{\mathrm{f}}-50{ }^{\circ} \mathrm{C}\right)$ [11]. The addition of 5\% $\mathrm{Mn}$ to the base steel decreased both the stretch formability and stretch flangeability of the steel.

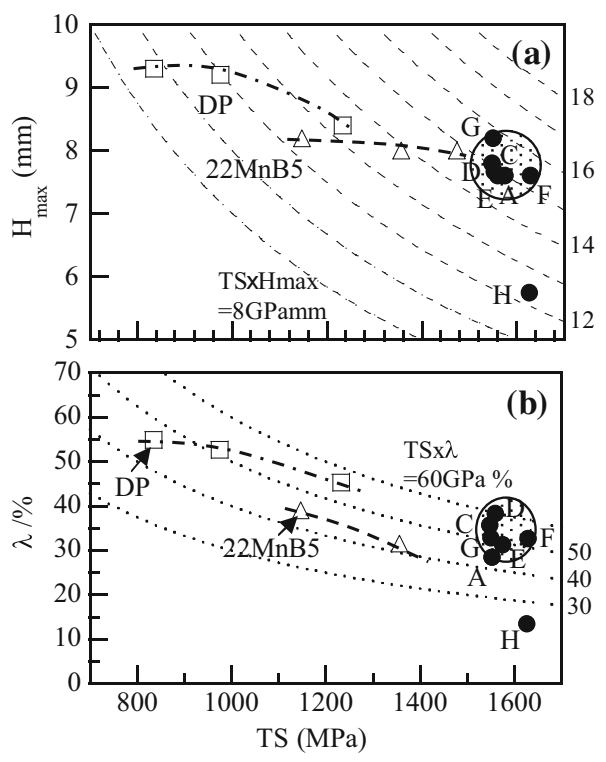

Fig. 11 Relationships between (a) maximum stretch height $\left(H_{\max }\right)$ and (b) hole-expanding ratio $(\lambda)$ and tensile strength (TS) in TM steels (Steels A and C-H). DP: $0.082 \% \mathrm{C}-0.88 \% \mathrm{Si}-2.0 \% \mathrm{Mn}$ dual-phase steel.22MnB5: $0.23 \% \mathrm{C}-0.19 \% \mathrm{Si}-1.29 \% \mathrm{Mn}-0.21 \% \mathrm{Cr}-$ $0.024 \% \mathrm{Ti}-0.003 \% \mathrm{~V}-0.003 \% \mathrm{~B}$ martensitic steel

\section{Toughness}

Figure 12 shows the CIAV at $20{ }^{\circ} \mathrm{C}$ and the DBTT of TM steels (Steels A and $\mathrm{C}-\mathrm{H}$ in Table 1) [16, 29-31]. From this, it can be seen that when $1 \% \mathrm{Cr}, 1 \% \mathrm{Cr}-0.2 \% \mathrm{Mo}$, or $1 \% \mathrm{Cr}-0.2 \% \mathrm{Mo}-1.5 \% \mathrm{Ni}$ is added to the base steel, the resulting TM steel exhibits a high CIAV ranging from 100 to $120 \mathrm{~J} / \mathrm{cm}^{2}$, and a low DBTT that ranges from -150 to $-130{ }^{\circ} \mathrm{C}$. Moreover, it also exhibits a tensile strength of approximately $1.5 \mathrm{GPa}$. The impact properties (CIAV and DBTT) of the alloyed TM steels are far superior to those of conventional martensitic steels. On the other hand, the combination of TS and CIAV $(\mathrm{TS} \times \mathrm{CIAV})$ is nearly the same as that of TBF steels (Steels C-E), although the DBTT is improved as compared to TBF steels (Steels C-E). From the load-displacement curves obtained by impact testing, it was found that this higher CIAV of TM steels is caused by the high crack propagation energy, not by the crack initiation energy.

Figure 13 shows typical SEM images and the illustrations of ductile and brittle impact fractures of TM steel [16], in which MA-like phases play an important role in suppressing void formation and preferential void growth at the MA-like phase/matrix interface (Fig. 13a). Furthermore, the MA-like phases also inhibit the initiation of cleavage cracking, as shown in Fig. 13(b), through the plastic relaxation that occurs as a result of the strain- 
induced transformation of the retained austenite. With this is in mind, the superior impact toughness of TM steel is believed to be caused by the presence of (i) a softened wide lath-martensite matrix, which contains only a small amount of carbide and hence has a lower carbon concentration, (ii) a large quantity of a finely dispersed MAlike phase, and (iii) a metastable retained austenite phase that occupies 2-4 vol\% of the MA-like phase, which subsequently leads to plastic relaxation via its strain-induced transformation.
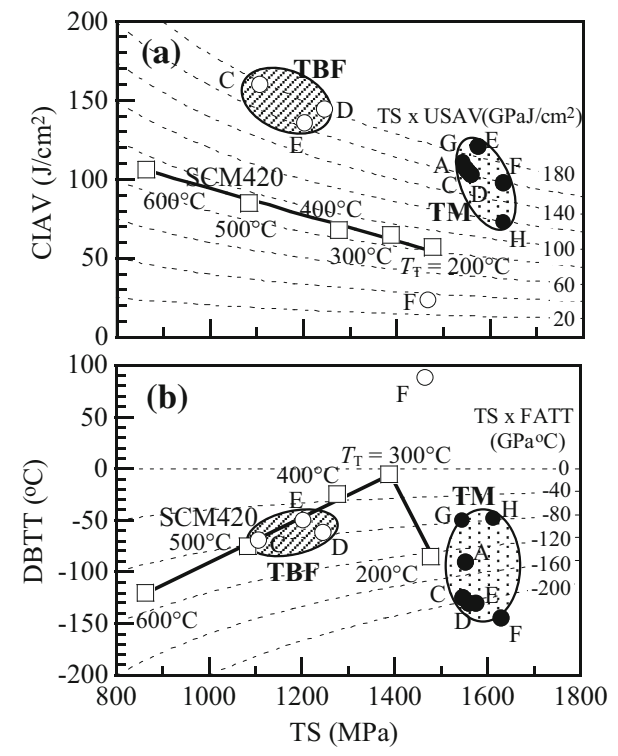

Fig. 12 Relationships between (a) upper-shelf CIAV and (b) ductilebrittle transition temperature (DBTT) and tensile strength (TS) for TM steels (Steels A and C-H) (filled circle), SCM420 steel tempered at $200-600{ }^{\circ} \mathrm{C}$ for $3600 \mathrm{~s}$ (open square), and TRIP-aided bainitic ferrite (TBF) steels (open circle) [12], which had the same compositions as Steels A and $\mathrm{C}-\mathrm{H}$ but were austempered at $400{ }^{\circ} \mathrm{C}$ for $1000 \mathrm{~s}$

\section{Fatigue Strength}

Figure 14 shows the fatigue limits of smooth and notched specimens $\left(\mathrm{FL}, \mathrm{FL}_{\mathrm{N}}\right)$ and the notch sensitivity $(q)$ of $\mathrm{TM}$ steels [19]. Note that the notch sensitivity is defined by the following equation [32]:

$q=\left(K_{\mathrm{f}}-1\right) /\left(K_{\mathrm{t}}-1\right)$,

where $K_{\mathrm{f}}$ and $K_{\mathrm{t}}$ are the fatigue notch factor $\left(=\mathrm{FL} / \mathrm{FL}_{\mathrm{N}}\right)$ and stress concentration factor $\left(K_{\mathrm{t}}=1.9\right.$ in this study), respectively.

When TM steels containing $0.2-0.4 \% \mathrm{C}$ (Steels J-L) were subjected to heat treatment during the IT process at $50{ }^{\circ} \mathrm{C}$ and subsequent partitioning at $250{ }^{\circ} \mathrm{C}$, much higher notch-fatigue limits and lower notch sensitivities were obtained as compared with SCM420, SCM435, and SCM440 structural steels. In general, the fatigue limits of smooth and notched specimens are predominantly controlled by fatigue crack initiation and the crack propagation stages, respectively. Figure 15 shows an SEM image and an illustration of a crack formed on a notched-surface specimen of TM steel [19]. Note that in Fig. 14(b), $d_{\mathrm{Y}}$ is the plastic zone size, which is defined by the following equation [33]:

$d_{\mathrm{Y}}=K^{2} /\left(3 \pi \mathrm{YS}^{2}\right)$,

where YS is the yield stress, $K$ is the stress intensity factor defined as $\sigma(\pi c)^{1 / 2}, \sigma$ is the applied stress, and $c$ is the crack length. In Fig. 15(a), it appears that a fatigue crack initiates in the wide lath-martensite structure but is stopped at the MA-like phase. Because a small amount of retained austenite is always present within the plastic zone, the higher notch fatigue limits of Steels J-L can be considered to be principally associated with the following factors, all of which could potentially contribute to inhibiting fatigue crack initiation and/or propagation:

\section{[Impact ductile fracture]}

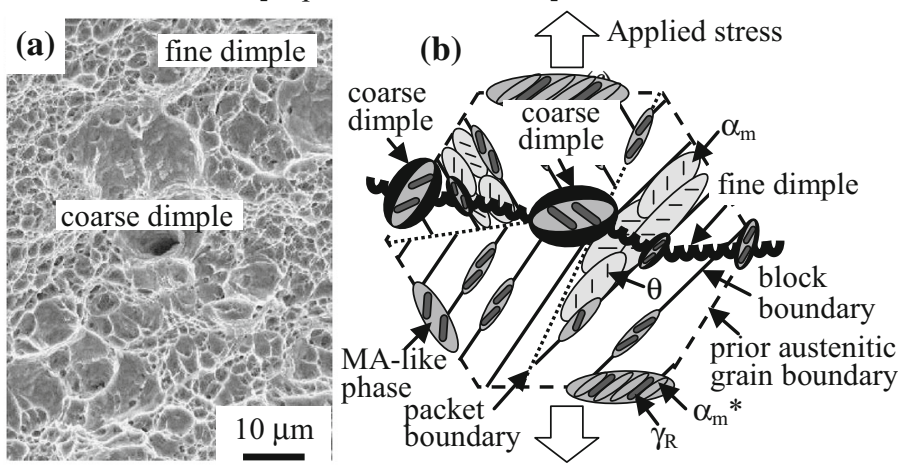

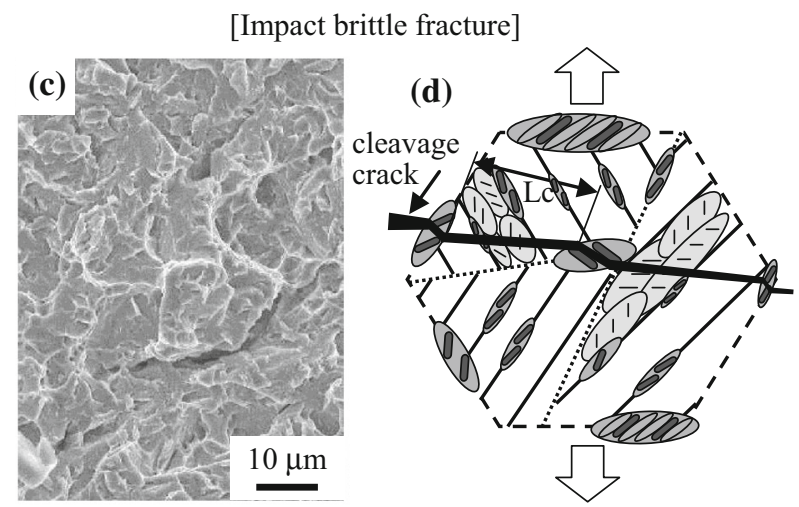

Fig. 13 Typical SEM images and Illustrations showing (a, b) ductile and $(\mathbf{c}, \mathbf{d})$ brittle impact fractures for TM steels. $L \mathrm{c}$ : quasi-cleavage crack path affected by MA-like phase located on packet and block boundaries. $\alpha_{\mathrm{m}}, \alpha_{\mathrm{m}}^{*}, \gamma_{\mathrm{R}}$, and $\theta$ represent wide lath-martensite, narrow lath-martensite, retained austenite, and carbide, respectively 


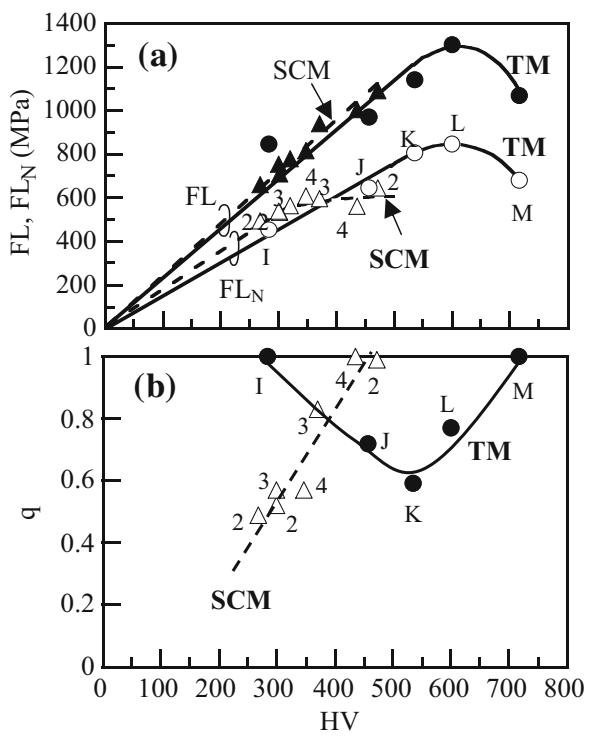

Fig. 14 Variations in (a) fatigue limits of smooth and notched specimens $\left(\mathrm{FL}, \mathrm{FL}_{\mathrm{N}}\right)$ and (b) notch sensitivity $(q)$ as a function of Vickers hardness (HV) in TM (Steels I-M) (open circle, filled circle), SCM420- (2), SCM435- (3), and SCM440- (4) type steels (open triangle, filled triangle; $\mathrm{SCM})$
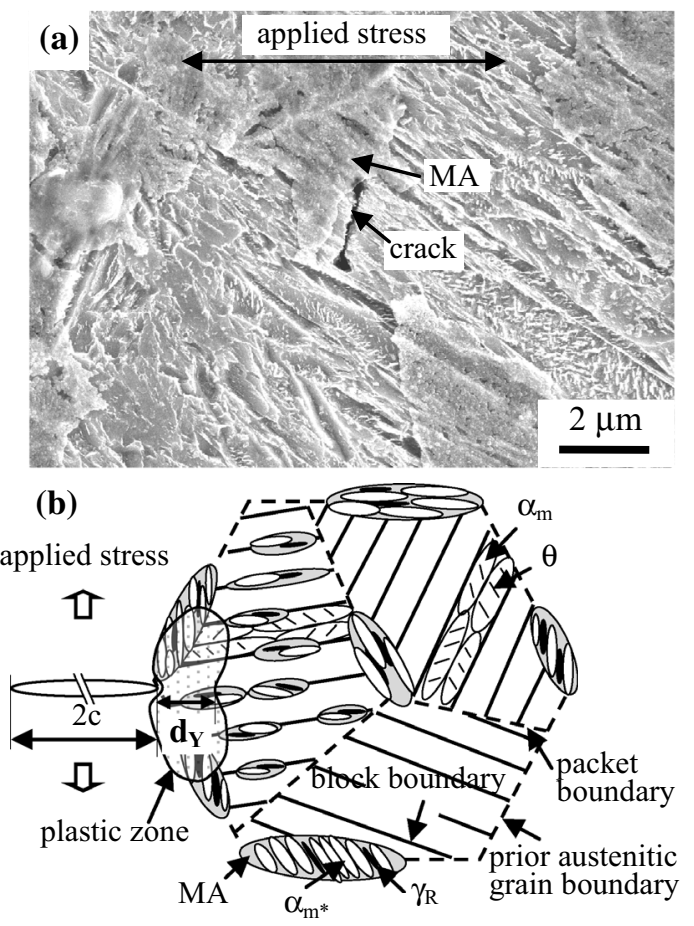

Fig. 15 (a) SEM image of the initial crack formed on the notched surface of TM steel (Steel J) fractured at $N_{\mathrm{f}}=5.0 \times 10^{4}$ cycles. (b) Illustration of the plastic zone size $\left(d_{\mathrm{Y}}\right)$ in TM steel depicting the crack tip and distribution of MA phases, where $\alpha_{\mathrm{m}}, \alpha_{\mathrm{m}}^{*}, \gamma_{\mathrm{R}}$, and $\theta$ represent wide lath-martensite, narrow lath-martensite, retained austenite, and carbide, respectively

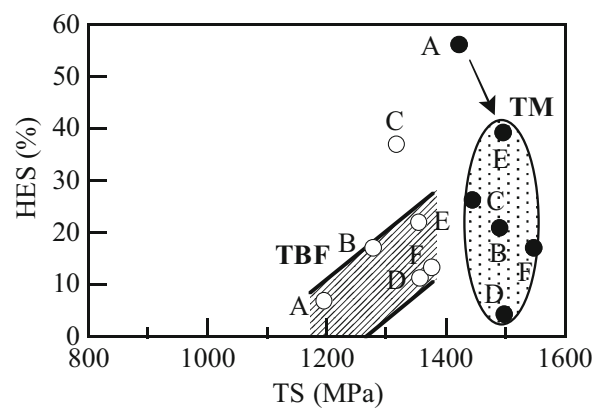

Fig. 16 Relationship between hydrogen embrittlement susceptibility (HES) and tensile strength (TS) of TM and TBF steels (Steels A-F)

(1) Plastic relaxation of localized stress concentrations as a result of the strain-induced transformation of 3-5 vol\% metastable retained austenite.

(2) A large quantity of finely dispersed MA-like phases along the prior austenitic, packet, and block boundaries.

(3) A low concentration of carbide in the wide lathmartensite structure.

\section{Delayed Fracture Strength}

Figure 16 shows the HES value of TBF and TM steels (Steels A-F) [20] as defined by Eq 2.

This result shows that the HES values of TM steels are almost the same as those of TBF steels; however, the TM steels possess a higher yield and tensile strength. It is the addition of alloying elements that is responsible for the lowered HES values of TM steel, particularly in Steel D, whereas the HESs of TBF steels actually increase by micro-alloying.

Figure 17 shows typical hydrogen evolution rate-temperature curves for TBF and TM steels (Steels A and D). It was found that a larger amount of diffusible hydrogen was absorbed in Steel D (TBF and TM steels) than in Steel A. This indicates that low HES value of Steel D was associated with highly charged diffusible hydrogen.

Figure 18 shows the relationship between the HES values and the original volume fraction and carbon concentration of retained austenite for TBF and TM steels (Steels A-F). The figure shows that the HES values of TBF steels decreased with increasing original volume fraction and carbon concentration of retained austenite, whereas only the original carbon concentration influenced the HES values of TM steel. Typically, the hydrogen concentration on the prior austenitic grain and lath boundaries is reduced by the presence of metastable retained austenite because most of the hydrogen is retained in the retained austenite and the austenite/matrix interface [34]. Consequently, the low HES value of Steel D is 




Fig. 17 Hydrogen evolution rate-temperature $(\mathrm{d} H / \mathrm{d} t-T)$ curves of TBF and TM steels (Steels A and D)
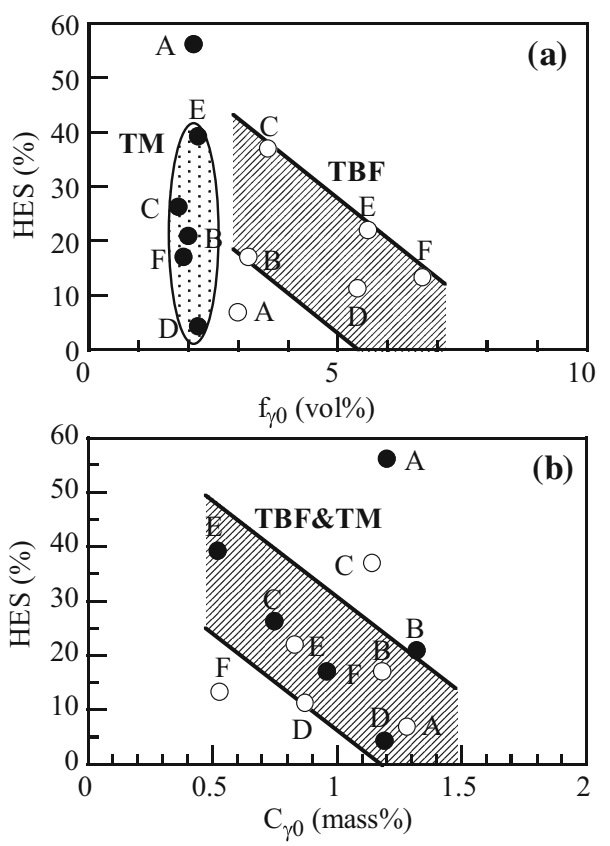

Fig. 18 Relationships between hydrogen embrittlement susceptibility $(H E S)$ and (a) original volume fraction $\left(f \gamma_{0}\right)$ and (b) carbon concentration $\left(C \gamma_{0}\right)$ of retained austenite for TM and TBF steels (Steels A-F). Open and solid marks represent data of TBF and TM steels, respectively

attributable to its high stability and volume fraction of retained austenite, which effectively traps most of the hydrogen and suppresses the fracture of the prior austenitic grain boundaries. In this case, it is also considered that the strain-induced transformation of the retained austenite discharges this hydrogen, but that it is then diffused into surrounding regions of retained austenite.

\section{Prospective Applications}

It was introduced in this paper that TM steel has excellent mechanical properties in comparison with conventional martensitic steel. The mechanical properties are expected to be improved further by increasing retained austenite fraction and structure-refining. Therefore, TM steel may be suitable for hot stamping (hot press forming) of sheet [35] and hot forging of wire and bar. In fact, Sugimoto et al. have confirmed that hot forging at 50\% strain and subsequent IT process improved considerably impact toughness of TM steel [30, 36].

If the hot-forged parts are served as automotive drivetrain parts, surface hardening treatment such as carburizing and/or fine particle peening is effective to increase fatigue strength. In particular, fine particle peening can enhance the fatigue strength by increase in surface hardening and the compressive residual stress, with a small surface roughness, which resulted from strain-induced martensite transformation of retained austenite [28, 37].

Open Access This article is distributed under the terms of the Creative Commons Attribution 4.0 International License (http://crea tivecommons.org/licenses/by/4.0/), which permits unrestricted use, distribution, and reproduction in any medium, provided you give appropriate credit to the original author(s) and the source, provide a link to the Creative Commons license, and indicate if changes were made.

\section{References}

1. V.F. Zackay, E.R. Parker, D. Fahr, D.R. Bush, The enhancement of ductility in high-strength steels. Trans. Am. Soc. Met. 60, 252-259 (1967)

2. O. Matsumura, Y. Sakuma, H. Takechi, Enhancement of elongation by retained austenite in intercritical annealed $0.4 \mathrm{C}-1.5 \mathrm{Si}-$ 0.8Mn steel. Trans. Iron Steel Inst. Jpn. 27, 570-579 (1987)

3. K. Sugimoto, N. Usui, M. Kobayashi, S. Hashimoto, Effects of volume fraction and stability of retained austenite on ductility of TRIP-aided dual-phase steels. ISIJ Int. 32, 1311-1318 (1992)

4. K. Sugimoto, M. Kobayashi, S. Yasuki, Cyclic deformation behavior of a transformation-induced plasticity-aided dual-phase steel. Metall. Trans. A 28A, 2637-2643 (1997)

5. A.K. Srivastava, D. Bhattacharjee, G. Jha, N. Gope, S.B. Singh, Microstructural and mechanical characterization of $\mathrm{C}-\mathrm{Mn}-\mathrm{Al}-\mathrm{Si}$ cold-rolled TRIP-aided steel. Mat. Sci. Eng. A 445-446, 549-557 (2007)

6. K. Sugimoto, M. Murata, S. Song, Formability of Al-Nb bearing ultrahigh-strength TRIP-aided sheet steels with bainitic ferrite and/or martensite matrix. ISIJ Int. 50, 162-168 (2010)

7. K. Sugimoto, J. Kobayashi, Newly developed TRIP-aided martensiticsteels. In Proceedings of MS\&T 2010 (TMS, Warrendale, 2010), pp. 1639-1649

8. J. Kobayashi, D.V. Pham, K. Sugimoto, Stretch-flangeability of 1.5GPa grade TRIP-aided martensitic cold rolled sheet steels. Steel Res. Int. (Special Edition, ICTP2011) (2011), pp. 598-603

9. J. Kobayashi, S. Song, K. Sugimoto, Ultra high-strength TRIPaided martensitic steels. ISIJ Int. 52, 1134-1139 (2012)

10. K. Sugimoto, J. Kobayashi, D.V. Pham, Advanced ultrahighstrength TRIP-aided martensitic sheet steels for automotive applications. In Proceedings of AIST 2013 (AIST, Warrendale, 2013), pp. 175-184

11. D.V. Pham, J. Kobayashi, K. Sugimoto, Effects of microalloying on stretch-flangeability of TRIP-aided martensitic sheet steel. ISIJ Int. 54, 1943-1951 (2014) 
12. J.G. Speer, D.V. Edmonds, F.C. Rizzo, D.K. Matlock, Partitioning of carbon from supersaturated plates of ferrite with application to steel processing and fundamentals of the bainitic transformation. Curr. Opinion Solid State Mat. Sci. 8, 219-237 (2004)

13. W. Cao, J. Shi, C. Wang, L. Xu, M. Wang, H. Dong, The 3rd generation automobile sheet steels presenting with ultrahigh strength and high ductility. In Proceedings of ICAS 2010 (Metall. Ind. Press, Beijing, 2010), pp. 196-215

14. U. Brux, G. Frommeyer, O. Grassel, L.W. Meyer, A. Weise, Development and characterization of high strength impact resistant Fe-Mn-(Al-Si) TRIP/TWIP steels. Steel Res. Int. 73, 294-298 (2002)

15. J. Kobayashi, D. Ina, K. Sugimoto (2012) Fracture toughness of a 1.5 GPa grade C-Si-Mn-Cr-Nb TRIP-aided martensitic steels. In Proceedings of MS\&T 2012 (TMS, Warrendale, 2012), pp. 937-944

16. J. Kobayashi, D. Ina, K. Sugimoto, Effects of microalloying on the impact toughness of ultrahigh-strength TRIP-aided martensitic steels. Metall. Mater. Trans. A 44A, 5006-5017 (2013)

17. J. Kobayashi, D. Ina, A. Futamura, K. Sugimoto, Fracture toughness of an advanced ultrahigh-strength TRIP-aided steels. ISIJ Int. 54, 955-962 (2014)

18. N. Yoshikawa, J. Kobayashi, K. Sugimoto, Notch fatigue properties of advanced TRIP-aided bainitic ferrite steels. Metall. Mater. Trans. A 43A, 4129-4136 (2012)

19. J. Kobayashi, N. Yoshikawa, K. Sugimoto, Notch-fatigue strength of advanced TRIP-aided martensitic steels. ISIJ Int. 53, 1479-1486 (2013)

20. T. Hojo, J. Kobayashi, K. Sugimoto (2012) Hydrogen embrittlement resistances of alloying elements adding ultra high strength low alloy TRIP-aided steels. In Proceedings of MS\&T 2012 (TMS, Warrendale, 2012), pp. 1186-1192

21. H. Maruyama, X-ray measurement of retained austenite volume fraction. J. Jpn. Soc. Heat Treat. 17, 198-204 (1977). (in Japansese)

22. D.J. Dyson, B. Holmes, Effect of alloying additions on the lattice parameter of austenite. J. Iron Steel Inst. 208, 469-474 (1970)

23. B.C. De Cooman, Structure-properties relationship in TRIP steels containing carbide-free bainite. Curr. Opin. Solid State Mater. Sci. 8, 285-303 (2004)
24. D.P. Koistinen, R.E. Marburger, A general equation describing the extent of the austenite-martensite transformation in pure ironcarbon alloys and plain carbon steel. Acta Metall. 7, 59-60 (1959)

25. Y.W. Chang, R.J. Asaro, Bauschinger effects and work-hardening in spheroidized steels. Met. Sci. 12, 277-284 (1978)

26. M.F. Ashby, Work hardening of dispersion-hardened crystals. Philos. Mag. 14, 1157-1178 (1966)

27. T. Mura, T. Mori, Micromechanics (Baifukan, Tokyo, 1976), p. 23

28. M. Natori, S. Song, K. Sugimoto, Effects of fine particle peening on surface residual stress of a TRIP-aided bainitic ferrite steel. J. Soc. Mat. Sci. Jpn. 63, 662-668 (2014)

29. K. Sugimoto, H. Tanino, J. Kobayashi, Stretch-flangeability of $0.2 \% \mathrm{C}-1.5 \% \mathrm{Si}-1.5-5 \% \mathrm{Mn}$ TRIP-aided martensitic steels. In Proceedings of MS\&T 2014 (TMS, Warrendale, 2014), pp. 281-290

30. K. Sugimoto, J. Kobayashi, T. Hojo, Ultrahigh-strength TRIPaided martensitic steels for hot-worked automotive drivetrain components. In Proceedings of SCT 2014 (Steel Institute VDEh, Düsseldorf, 2014), pp. 21-28

31. K. Sugimoto, H. Tanino, J. Kobayashi, Impact toughness of medium-Mn transformation-induced plasticity-aided steels. Steel Res. Int. (2015). doi:10.1002/srin.201400585

32. G.E. Dieter, Mechanical Metallurgy (SI Metric Edition) (McGraw-Hill Book Company, London, 1988), p. 403

33. J.F. Knott, Fundamentals of Fracture Mechanics (Baifukan, Tokyo, 1977), p. 127

34. T. Hojo, K. Sugimoto, Y. Mukai, S. Ikeda, Delayed fracture properties of aluminium bearing ultra high strength low alloy TRIP-aided steels. ISIJ Int. 48, 824-829 (2008)

35. http://automotive.arcelormittal.com/saturnus/sheets/E_EN.pdf. Accessed 28 April 2015

36. K. Sugimoto, J. Kobayashi, Y. Nakajima, T. Kochi, The effects of cooling rate on retained austenite characteristics of a $0.2 \mathrm{C}-1.5 \mathrm{Si}-$ $1.5 \mathrm{Mn}-1.0 \mathrm{Cr}-0.05 \mathrm{Nb}$ TRIP-aided martensitic steel. Mater. Sci. Forum 783-786, 1015-1020 (2014)

37. M. Natori, S. Song, K. Sugimoto, Effects of fine particle peening on fatigue properties of a TRIP-aided bainitic ferrite steel. Soc. Mater. Sci. Jpn. 64, 620-627 (2015) 